\title{
PD-L1 expression and patient outcomes in gastrointestinal neuroendocrine neoplasm: a meta-analysis
}

\author{
Woojoo Lee ${ }^{1 \#}$, Min-ju Kim ${ }^{2 \#}$, Younghee $\mathrm{Choi}^{3}$, Hyunchul Kim $^{4} \wedge$ \\ ${ }^{1}$ Department of Public Health Sciences, Graduate School of Public Health, Seoul National University, Seoul, Republic of Korea; ${ }^{2}$ Department of \\ Pathology, Soonchunhyang University College of Medicine, Bucheon Hospital, Gyeonggi-do, Republic of Korea; ${ }^{3}$ Department of Pathology, Hallym \\ University Dongtan Sacred Heart Hospital, Gyeonggi-do, Republic of Korea; ${ }^{4}$ Department of Pathology, CHA Ilsan Medical Center, Gyeonggi-do, \\ Republic of Korea \\ Contributions: (I) Conception and design: H Kim; (II) Administrative support: M Kim, Y Choi; (III) Provision of study materials or patients: H Kim; \\ (IV) Collection and assembly of data: M Kim, Y Choi; (V) Data analysis and interpretation: W Lee, H Kim; (VI) Manuscript writing: All authors; (VII) \\ Final approval of manuscript: All authors. \\ "These authors contributed equally to this work. \\ Correspondence to: Hyunchul Kim. Department of Pathology, CHA Ilsan Medical Center, 1205 Jungang-ro, Ilsandong-gu, Goyang-si, Gyeonggi-do, \\ 10414, Republic of Korea. Email: hyunchulk@chamc.co.kr.
}

Background: Programmed cell death ligand 1 (PD-L1) is a known prognostic and therapeutic marker in malignant tumors. This meta-analysis aimed to investigate the association of PD-L1 expression with the clinicopathological parameters and survival outcomes of gastrointestinal neuroendocrine neoplasms (NENs). Methods: PubMed, EMBASE, Web of Science, OVID Medline, the Cochrane Library, and Google Scholar were searched for relevant studies June 30, 2020. Studies reporting PD-L1 immunohistochemistry of gastrointestinal NEN with associated survival data or clinicopathological parameters were included.

Results: In total, 10 studies were included. Odd ratios (ORs) were combined to evaluate association between PD-L1 expression and clinicopathological parameters. Hazard ratios (HR) and standard errors were combined to evaluate the association between PD-L1 expression and overall survival. PD-L1 expression was significantly associated with higher tumor grade [OR: 3.42; 95\% confidence interval (CI): 2.00-5.85, $\mathrm{P}<0.05$ ] and lymph node metastasis (OR: 1.94; 95\% CI: 1.13-3.34, P=0.02). However, PD-L1 expression was not associated with age, sex, and tumor stage. The pooled hazard ratio (HR: 2.45, 95\% CI: 1.20-4.98, P<0.05) showed a significant association between PD-L1 expression and shorter overall survival.

Discussion: The results of this meta-analysis show that PD-L1 expression in tumor cells of gastrointestinal NEN can be used as a biomarker of worse survival and important clinicopathological parameters. Further, it can also be used as a therapeutic biomarker for developing novel treatment modalities that can improve prognosis. Although the results of this meta-analysis are more robust than those of the individual studies analyzed, this study also has several limitations. Further studies with a larger study population and consistent method for evaluating PD-L1 expression are needed to validate our results.

Keywords: Programmed cell death ligand 1 (PD-L1); neuroendocrine neoplasm (NEN); prognosis; clinicopathological features; meta-analysis

Submitted Dec 21, 2020. Accepted for publication Mar 24, 2021.

doi: $10.21037 /$ tcr-20-3482

View this article at: http://dx.doi.org/10.21037/tcr-20-3482

^ ORCID: 0000-0002-9322-725X. 


\section{Introduction}

Neuroendocrine neoplasms (NENs) are malignant epithelial tumors with neuroendocrine differentiation (1). NENs are relatively rare, but their incidence has been increasing recently (2). The tumor is ubiquitous, and the gastrointestinal system is one of the prevalent anatomical sites (3). NENs are classified into neuroendocrine tumors (NETs) and neuroendocrine carcinomas (NECs), which present relatively aggressive clinical behavior. NET is further graded into G1, G2, and G3 based on histopathological characteristics including tumor cell morphology, mitotic rate, and Ki-67 index (1). The grading system was devised to provide prognostic information, and efforts to identify better prognostic markers are ongoing (4).

Recent advances in immunotherapy have generated increased research attention on tumor expression of programmed cell death ligand 1 (PD-L1, also known as CD274 and B7-H1) expression as a biomarker for predicting prognosis and determining a patient's eligibility for targeted therapy (5). PD-L1 is a ligand for the programmed cell death 1 (PD-1) receptor. The binding between PD-L1 and PD-1 causes apoptosis of activated T cells, and tumor cells survive by escaping host immunity through the mechanism (6). Increasing research on PD-L1 expression and its prognostic and clinicopathological value have in turn led to expanding application of PD-L1 inhibitors $(7,8)$. In gastrointestinal NENs, several studies have reported that PD-L1 expression is associated with survival and clinicopathological parameters (9-18). However, these studies were relatively small scale.

Therefore, this meta-analysis aimed to evaluate whether PD-L1 expression was associated with the prognosis and clinicopathological characteristics of gastrointestinal NEN patients.

We present the following article in accordance with the Preferred Reporting Items for Systematic Reviews and Meta-analyses (PRISMA) reporting checklist (available at http://dx.doi.org/10.21037/tcr-20-3482).

\section{Methods}

\section{Study design and search strategy}

PubMed, EMBASE, Web of Science, OVID Medline, the Cochrane Library, and Google scholar were searched for relevant articles on June 30, 2020 using the following keywords: ("PD-L1" or "PDL1" or "CD274" or "B7-H1") and ("neuroendocrine" or "small cell carcinoma" or "merkel cell carcinoma" or "carcinoid"). Two authors (Younghee Choi and Hyunchul Kim) independently reviewed the results.

\section{Selection criteria}

Studies were selected if they met the following criteria: (I) the NETs were histopathologically diagnosed; (II) PDL1 expression was evaluated via immunohistochemistry; (III) the association between PD-L1 expression and clinicopathological characteristics or prognostic outcomes was evaluated. Studies were excluded according to the following criteria: (I) study type other than research articles (e.g., case reports, review, comment, or errata), (II) conference abstract, (III) non-English articles, (IV) non-human or non-clinical studies, (V) the patients had metastatic tumors or were previously treated, (VI) insufficient data, (VII) duplicate publication, and (VIII) analysis of tumor PD-L1 expression in organs other than those in the gastrointestinal system.

\section{Data extraction}

Two authors (Younghee Choi and Hyunchul Kim) independently extracted the following information: first author, publication year, country of study, tumor type and anatomical location, antibody information (manufacturing company, clone, type, dilution, and cut-off value), number of patients, number of PD-L1-positive and negative patients, and various clinicopathological characteristics (age, sex, tumor grade, tumor stage, and lymph node metastasis).

Survival data were extracted from Kaplan Meier curves using the Engauge Digitizer software, version 12.1 (RRID:SCR_019056). Hazard ratios (HRs) were then recalculated using the method reported by Tierney et al. (19).

\section{Quality assessment}

Two authors (Younghee Choi and Hyunchul Kim) independently assessed the quality of the studies included in this meta-analysis using the Newcastle-Ottawa Quality Assessment Scale (NOS) (Table S1). Consensus for disagreement between the two authors was reached through discussion.

\section{Statistical analyses}

Odds ratios (ORs) were combined to evaluate 


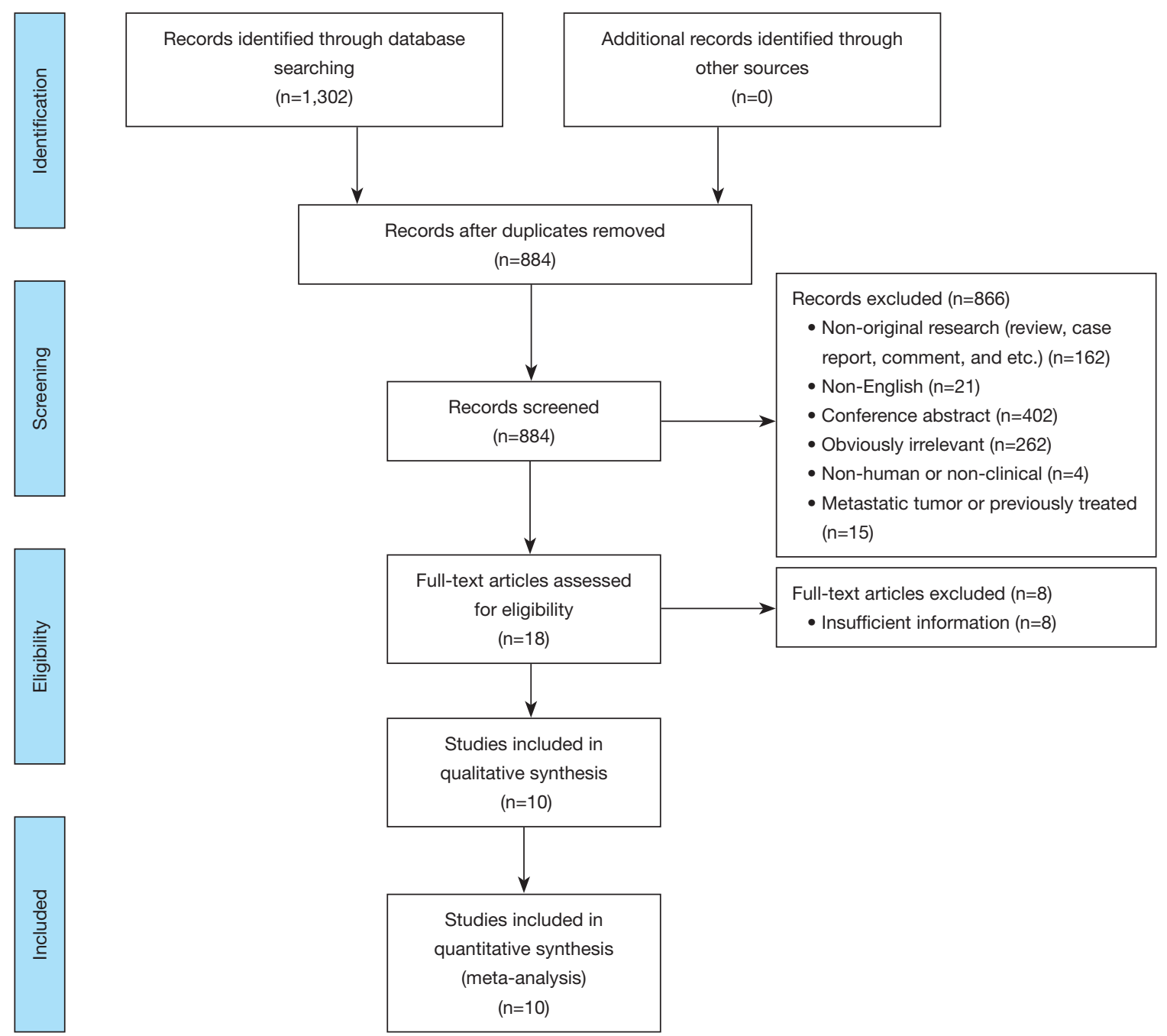

Figure 1 Flow diagram depicting the study selection process.

the association between PD-L1 expression and clinicopathological parameters. Meanwhile, HRs and standard errors were combined to evaluate the association between PD-L1 expression and overall survival. Log OR and $\log$ HR were used for analysis. The $\mathrm{I}^{2}$ value was used to evaluate heterogeneity, with $\mathrm{I}^{2}>50 \%$ regarded as considerable heterogeneity. A random effects model was adopted when considerable heterogeneity was present, whereas a fixed effect model was adopted when heterogeneity was negligible. Publication bias was assessed with Egger's test, Begg's test, and funnel plot for HRs. All statistical analysis were performed using the “meta" packages of R, version 3.5.3 (RRID:SCR_019055) $(20,21)$. A P value of $<0.05$ was considered statistically significant.

\section{Results}

\section{Characteristics of the included studies}

Of the 1,302 articles retrieved from the literature search, we initially excluded 1,284 duplicate $(\mathrm{n}=418)$ and ineligible articles (e.g., case report, review article, conference abstract, non-original article, and non-English; n=866) after reviewing the title and abstract. Eight articles were then further excluded due to lack of sufficient information after a full-text review. Finally, 10 studies were included in the meta-analysis (Figure 1).

The characteristics of the studies are summarized in Table 1. The studies were reported from Germany, Italy, USA, Turkey, China, and Japan between 2016 and 2019. A total of 931 cases were included in the pooled analysis. Four of the 
Table 1 Characteristics of studies included in meta-analysis

\begin{tabular}{|c|c|c|c|c|c|c|c|}
\hline Study & Country & $\begin{array}{l}\text { Number of } \\
\text { patients }\end{array}$ & Tumor type & $\begin{array}{l}\text { PD-L1 antibody } \\
\text { manufacturer }\end{array}$ & $\begin{array}{c}\text { PD-L1 } \\
\text { antibody clone }\end{array}$ & $\begin{array}{l}\text { PD-L1 antibody } \\
\text { dilution }\end{array}$ & $\begin{array}{l}\text { Cutoff for PD-L1 } \\
\text { positivity }\end{array}$ \\
\hline Bösch 2019 & Germany & 251 & GEP-NEN & Cell Signaling Technology & E1L3N & $1: 100$ & $>1 \%$ \\
\hline $\begin{array}{l}\text { Cavalcanti } \\
2017\end{array}$ & Italy & 57 & GEP-NEN & Cell Signaling Technology & E1L3N & $1: 600$ & $\begin{array}{l}\text { Combined } \\
\text { score } \geq 2\end{array}$ \\
\hline Huang 2016 & China & 78 & Esophageal SCC & Proteintech Group Inc. & $\mathrm{N} / \mathrm{A}$ & $\mathrm{N} / \mathrm{A}$ & H score $\geq 5$ \\
\hline Oktay 2019 & Turkey & 59 & GEP-NEN & Abcam & $28-8$ & $1: 100$ & $\mathrm{~N} / \mathrm{A}$ \\
\hline Ono 2018 & Japan & 136 & Gastrointestinal NEN & $\mathrm{N} / \mathrm{A}$ & $\mathrm{N} / \mathrm{A}$ & $\mathrm{N} / \mathrm{A}$ & $\mathrm{N} / \mathrm{A}$ \\
\hline Wang 2019 & China & 120 & GEP-NEN & Abcam & $28-8$ & $1: 50$ & $\begin{array}{c}\text { Combined } \\
\text { score }>3\end{array}$ \\
\hline Yang 2019 & China & 43 & Gastric NEC & Abcam & $28-8$ & $1: 500$ & $\begin{array}{c}\text { Combined } \\
\text { score } \geq 4\end{array}$ \\
\hline
\end{tabular}

*, data of $1 \%$ cut off was used for this meta-analysis. GEP-NEN, gastroenteropancreatic-neuroendocrine neoplasia; NET, neuroendocrine tumor; SCC, small cell carcinoma; NEC, neuroendocrine carcinoma; N/A, not available.

studies used PD-L1 antibody from Abcam (Cambridge, UK) (clone 28-8, RRID:AB_2811063), two used E1L3N clone from Cell Signaling Technology (Danvers, Massachusetts, USA) (RRID:AB_2687655), one used 22C3 clone from Dako (Glostrup, Denmark) (RRID:AB_2833074), and two did not specify the manufacturer. Cutoffs for interpretation of PD-L1 immunohistochemistry varied: three studies applied $1 \%$ as a cutoff, three studies combined stain intensity score and percentage score, one study applied $\mathrm{H}$ score, one study reported data using two different cutoffs of $1 \%$ and $50 \%$, and two studies did not specify the cutoffs. For the study with two different cutoffs, we selected the data with $1 \%$ cutoff in accordance with other included studies. All included studies were retrospective studies with similar study structure. Further, all studies had relatively high quality, with NOS of 7.

\section{PD-L1 expression and clinicopathological characteristics}

Five studies analyzed gastroenteropancreatic neuroendocrine neoplasm (GEP-NEN) (one of them was high grade GEP-NEN); one, small bowel NET; one, esophageal small cell carcinoma; one, gastrointestinal NEN; one, digestive system NEC; and one, gastric NEC. The relationship between positive PD-L1 expression and clinicopathological characteristics is presented in Figure 2.
Age was analyzed in three studies that included 241 patients (Figure 2A) $(13,16,18)$. Of the 130 patients aged under 60 years, 69 patients were PD-L1 positive. Meanwhile, 57 patients were PD-L1 positive among 111 patients aged over 60 years. The pooled $\mathrm{OR}$ was not significant $(\mathrm{OR}=1.05$; 95\% CI, 0.63-1.76, $\mathrm{P}=0.85$ ).

Seven studies were analyzed for the correlation between PD-L1 expression and sex (Figure 2B) (11,13-18). In total, 134 of the 339 male patients were PD-L1 positive, whereas 59 of the 185 female patients were PD-L1 positive. The pooled $\mathrm{OR}$ was not significant $(\mathrm{OR}=1.11 ; 95 \% \mathrm{CI}, 0.74$ $1.68, \mathrm{P}=0.61)$. The association between tumor grade and PD-L1 expression was analyzed in five studies (Figure 2C) $(9,11,14-16)$. G1 and G2 tumor grade were categorized as low grade and G3 tumors and NECs were classified as high grade. Among the 481 and 122 patients with low- and highgrade tumors, 73 and 65 patients were PD-L1 positive, respectively. High tumor grade was significantly associated with PD-L1 expression (OR $=3.42 ; 95 \%$ CI, 2.00-5.85, $\mathrm{P}<0.0001$ ).

Three studies were evaluated for the correlation between lymph node metastasis and PD-L1 expression (Figure 2D) $(13,16,18)$. Two studies divided the patients into the node-positive and -negative groups $(13,16)$, whereas the remaining one study grouped them into the high node metastasis and low metastasis groups (18). Of the 114 


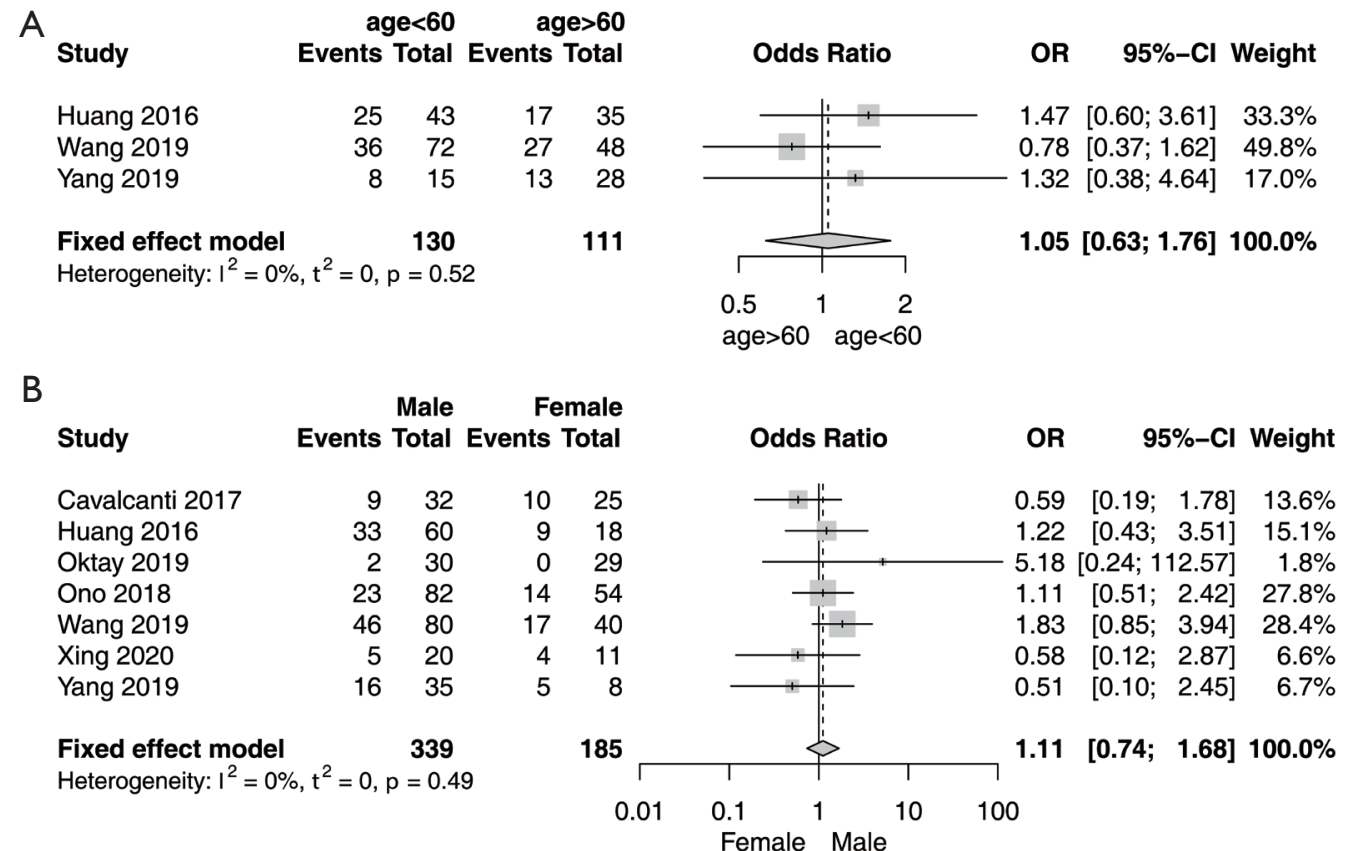

C Low grade High grade Events Total Events Total

Odds Ratio

$\begin{array}{lrrr}\text { Bosch 2019 } & 17 & 213 & 3 \\ \text { Cavalcanti 2017 } & 7 & 48 & 9 \\ \text { Oktay 2019 } & 0 & 47 & 2 \\ \text { Ono 2018 } & 27 & 120 & 10 \\ \text { Wang 2019 } & 22 & 53 & 41 \\ & & \\ \text { Fixed effect model } & 481 \\ \text { Heterogeneity: } \mathrm{I}^{2}=56 \%, \mathrm{t}^{2}=0.6131, \mathrm{p}=0.06\end{array}$

D

D

Study

\begin{tabular}{lrrrr} 
Huang 2016 & 13 & 22 & 29 & 5 \\
Wang 2019 & 40 & 61 & 23 & 5 \\
Yang 2019 & 15 & 31 & 6 & 12 \\
& & & & \\
Fixed effect model & \multicolumn{1}{c}{114} & & 127 \\
Heterogeneity: $\mathrm{I}^{2}=32 \%, \mathrm{t}^{2}=0.1221, \mathrm{p}=0.23$ &
\end{tabular}

E
LN+ LN-

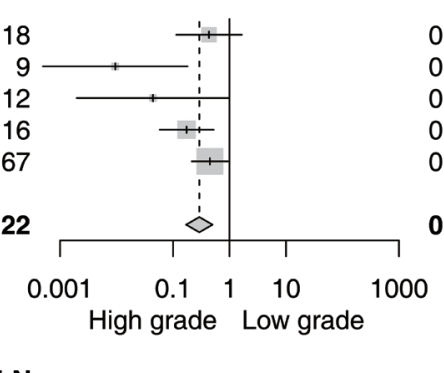

\section{OR $\quad 95 \%-C l$ Weight}

$0.43[0.11 ; 1.65] 16.2 \%$

$0.01[0.00 ; 0.18] \quad 3.3 \%$

$0.04[0.00 ; 0.99] \quad 3.0 \%$

$0.17[0.06 ; 0.52] 23.9 \%$

$0.45[0.22 ; 0.94] 53.5 \%$

$0.29[0.17 ; 0.50] 100.0 \%$
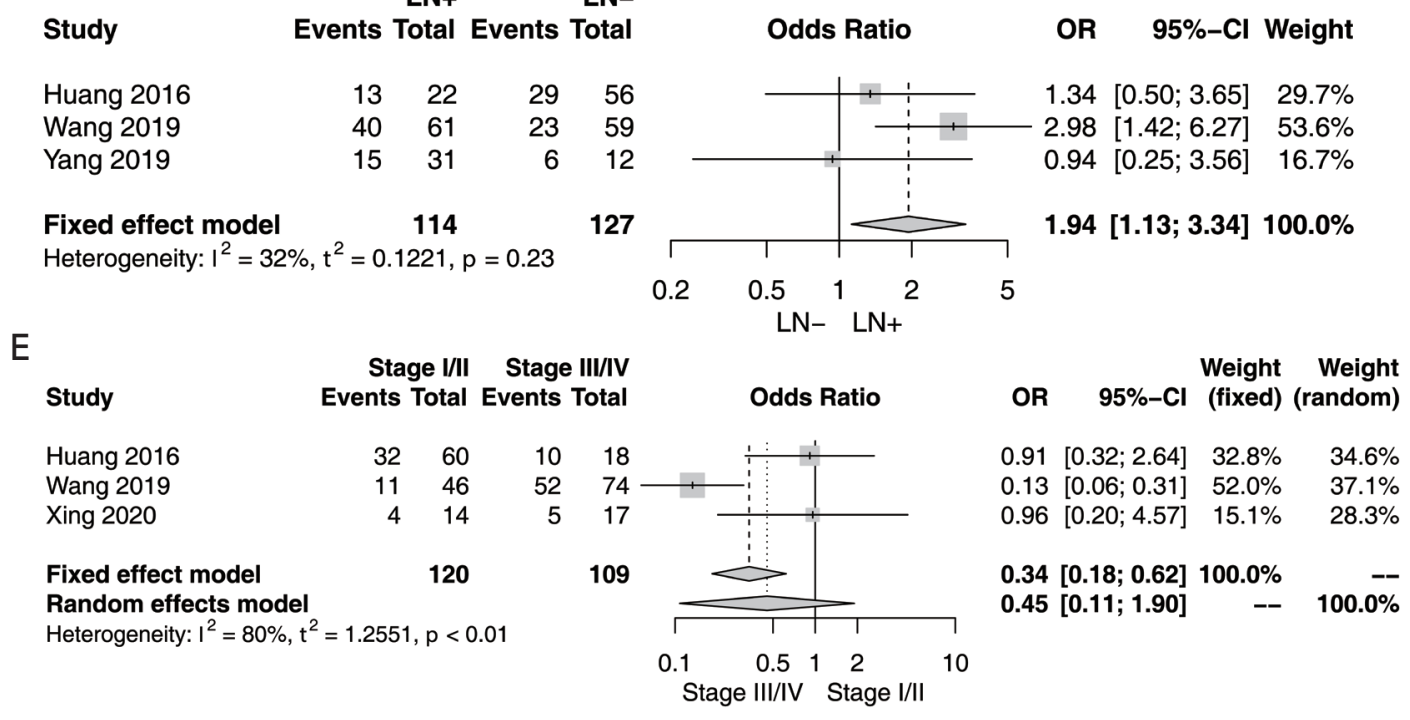

Figure 2 Forest plots of clinicopathological parameters associated with PD-L1 expression. (A) Age. (B) Gender. (C) Tumor grade. (D) Lymph node metastasis. (E) Tumor stage. 
Table 2 PD-L1 positive cases in clinicopathological characteristics of tumor grade, lymph node status, and stages from the studies included in the meta-analysis (positive cases/total cases)

\begin{tabular}{|c|c|c|c|c|c|c|}
\hline Study & Low grade & High grade & $\mathrm{LN}_{+}$ & LN- & Stage $1 / I I$ & Stage III/IV \\
\hline Cavalcanti 2017 & 7/48 (G1/2) & 9/9 (G3) & $\mathrm{N} / \mathrm{A}$ & $\mathrm{N} / \mathrm{A}$ & $\mathrm{N} / \mathrm{A}$ & $\mathrm{N} / \mathrm{A}$ \\
\hline Huang 2016 & N/A & N/A & $13 / 22$ & $29 / 56$ & $32 / 60$ & $10 / 18$ \\
\hline Oktay 2019 & 0/47 (G1/2) & 2/12 (G3) & N/A & N/A & $\mathrm{N} / \mathrm{A}$ & $\mathrm{N} / \mathrm{A}$ \\
\hline Wang 2019 & 22/53 (G1/2) & 41/67 (G3) & $40 / 61$ & $23 / 59$ & $11 / 46$ & $52 / 74$ \\
\hline Xing 2020 & $\mathrm{~N} / \mathrm{A}$ & N/A & $\mathrm{N} / \mathrm{A}$ & N/A & $4 / 14$ & $5 / 17$ \\
\hline Yang 2019 & N/A & N/A & $15 / 31^{*}$ & $6 / 12^{*}$ & $\mathrm{~N} / \mathrm{A}$ & $\mathrm{N} / \mathrm{A}$ \\
\hline
\end{tabular}

*, node metastasis status was divided into group of positive node 7 or less and more than 7. NEC, neuroendocrine carcinoma; LN+, lymph node metastasis positive; LN-, lymph node metastasis negative.

\begin{tabular}{|c|c|c|c|c|c|c|}
\hline Study & TE seTE & \multicolumn{2}{|c|}{ Hazard Ratio } & HR & $95 \%-\mathrm{Cl}$ & Weight \\
\hline Bosch 2019 & $2.23 \quad 0.3344$ & \multirow{7}{*}{+} & \multirow{2}{*}{$\frac{1}{+}$} & 9.33 & {$[4.84 ; 17.97]$} & $14.1 \%$ \\
\hline Busico 2019 & $1.50 \quad 0.1781$ & & & 4.50 & {$[3.17 ; 6.38]$} & $15.5 \%$ \\
\hline Cives 2019 & $0.49 \quad 0.2519$ & & + & 1.63 & {$[0.99 ; 2.67]$} & $14.9 \%$ \\
\hline Huang 2016 & $\begin{array}{ll}-0.58 & 0.1477\end{array}$ & & & 0.56 & {$[0.42 ; 0.75]$} & $15.7 \%$ \\
\hline Wang 2019 & $0.60 \quad 0.1216$ & & +1 & 1.83 & {$[1.44 ; 2.32]$} & $15.8 \%$ \\
\hline Xing 2020 & 2.240 .7340 & & \multirow[t]{2}{*}{+} & 9.35 & {$[2.22 ; 39.41]$} & $9.7 \%$ \\
\hline Yang 2019 & 0.360 .3170 & & & 1.43 & {$[0.77 ; 2.66]$} & $14.3 \%$ \\
\hline \multirow{2}{*}{\multicolumn{2}{|c|}{$\begin{array}{l}\text { Random effects model } \\
\text { Heterogeneity: } \mathrm{I}^{2}=95 \%, \mathrm{t}^{2}=0.8214, \mathrm{p}<0.01\end{array}$}} & \multicolumn{2}{|r|}{$\infty$} & \multirow[t]{2}{*}{2.45} & \multirow[t]{2}{*}[1.20;4.98]{} & \multirow[t]{2}{*}{$100.0 \%$} \\
\hline & & & & & & \\
\hline
\end{tabular}

Figure 3 Forest plot for HRs of OS in association with PD-L1 expression of tumor cells of gastrointestinal NEN. HR, hazard ratio; OS, overall survival; NEN, neuroendocrine neoplasm.

and 127 node-positive and -negative patients, 68 and 58 patients, respectively, were $\mathrm{PD}-\mathrm{L} 1$ positive. The pooled OR was significant $(\mathrm{OR}=1.94 ; 95 \% \mathrm{CI}, 1.13-3.34, \mathrm{P}=0.02)$.

Three studies were analyzed for the association between tumor stage and PD-L1 expression (Figure 2E) $(13,16,17)$. Of the 120 stage I/II cases and 109 stage III/IV cases, 47 and 67 cases, respectively, were PD-L1 positive. The pooled OR was not significant $(\mathrm{OR}=0.45 ; 95 \%$ CI, 0.11-1.90, $\mathrm{P}=0.28)$. Due to lack of heterogeneity, the fixed effect model was applied in the analysis of PD-L1 expression with age $\left(\mathrm{I}^{2}=0 \% ; \mathrm{P}=0.52\right)$, sex $\left(\mathrm{I}^{2}=0 \% ; \mathrm{P}=0.49\right)$, tumor grade $\left(\mathrm{I}^{2}=56 \%\right.$; $\mathrm{P}=0.06)$, and lymph node metastasis $\left(\mathrm{I}^{2}=32 \% ; \mathrm{P}=0.23\right)$. Meanwhile, the random effects model was employed in the analysis of the association between PD-L1 expression and tumor stage $\left(\mathrm{I}^{2}=80 \% ; \mathrm{P}<0.01\right)$ because considerable heterogeneity was present.
The numbers of cases in clinicopathological characteristics of tumor grade, lymph nod status, and stages are summarized in Table 2.

\section{PD-L1 expression and overall survival}

The result of the pooled analysis of HR for overall survival (OS) showed a significant association with PD-L1 expression (Figure 3). The combined HR was 2.45 (95\% CI, 1.20-4.98, $\mathrm{P}=0.01$ ). Significant heterogeneity was present in the analysis $\left(\mathrm{I}^{2}=94.9 \%, \mathrm{P}<0.05\right)$. Among the included studies, only one study by Huang et al. presented a contradictory result of better survival among the patients with positive PD-L1 expression. Significant heterogeneity remained on an additional analysis without the contradictory data from Huang et al. $\left(\mathrm{I}^{2}=88.2 \%, \mathrm{P}<0.05\right)$. 


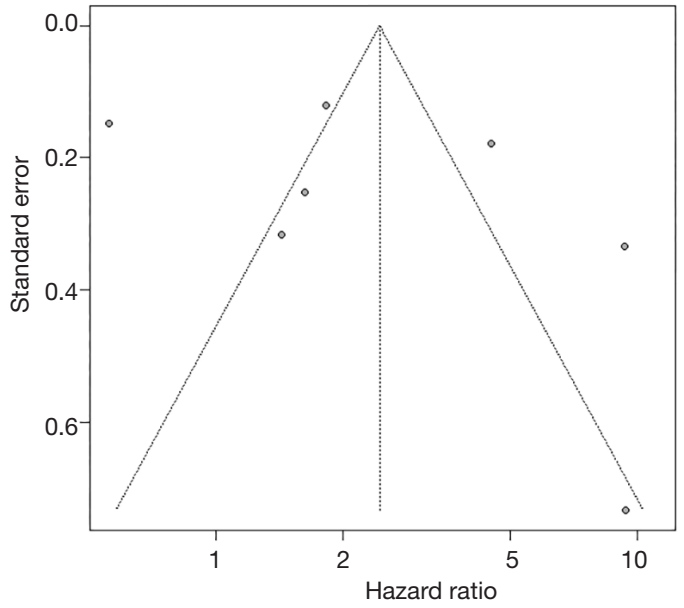

Figure 4 Funnel plot of HRs of studies included in meta-analysis. HR, hazard ratio.

\section{Publication bias}

The Funnel plot is presented in Figure 4. Begg's test $(\mathrm{P}=0.65)$ and Egger's test $(\mathrm{P}=0.36)$ did not show significant publication bias.

\section{Discussion}

PD-L1 expression in malignant tumors is known to be associated with not only worse prognosis, but also clinicopathological characteristics, such as lymph node metastasis and tumor grade $(7,8)$. However, the value of PD-L1 expression in gastrointestinal NEN remains unclear because of the relatively small sample size and conflicting findings in previous studies. This meta-analysis found that PD-L1 expression was significantly correlated with clinicopathological parameters and with higher tumor grade and lymph node metastasis. To our best knowledge, this is the first meta-analysis of PD-L1 expression in gastrointestinal NEN.

Increasing evidence on the importance of the PD-1/ PD-L1 pathway in the immune evasion mechanism of tumor cells has led to the expanding application of PDL1 inhibitors in various cancers (22). NEN is among the cancers receiving research attention for targeted immunotherapy (23).

Data showing the association between PD-L1 expression and lymph node metastasis need to be interpreted with caution because one of the studies categorized lymph node metastasis into node metastasis in $>7$ and $\leq 7$ lymph nodes (18), whereas other studies only classified lymph node metastasis into positive and negative. However, the individual study from Yang et al. showed an association between PD-L1 expression and low number of node metastasis, whereas the other study data showed the opposite findings.

Pooled analysis of HR of all the included studies showed significant results. A study by Huang et al. reported findings in contrast to those of other studies. The study reported better survival in patients with PD-L1-positive small cell esophageal carcinoma. The authors reported that although the underlying reason was unclear, a possible reason could be the higher aggressiveness of the small cell carcinoma compared to the other types of tumors (13). As previously stated, studies on small cell carcinoma in various organs showed better prognosis in PD-L1 positive groups. Further, the survival impact of PD-L1 expression might be different in small cell carcinomas compared with those in other NENs $(24,25)$.

Our result showed that PD-L1 expression has potential as both prognostic and therapeutic biomarker. Positive PDL1 expression was associated with lymph node metastasis and higher tumor grade, which are in turn related with poor prognosis. PD-L1 expression assay is becoming important in selecting eligible patients for immune checkpoint inhibitors, and the indications for PD-L1 inhibitors are also increasing $(22,26)$. Our results indicate the possibility that gastrointestinal NEN patients with positive PD-L1 expression can benefit from anti PD-L1 immunotherapy.

Although the results of this meta-analysis are more robust than those of the individual studies analyzed, this study also has several limitations. First, the PD-L1 antibodies varied among the included studies. Antibodies from different manufacturers yield different results, and this could have affected the results of study. Second, the methods for interpretation of PD-L1 immunohistochemistry also varied among the studies. Antibody dilution and the cutoff for PD-L1 positivity were different in each study. Third, the HRs had to be recomputed from the Kaplan-Meier curves because none of the included studies specified the HRs. Fourth, only OS had been pooled for prognostic information due to lack of data on progression-free survival. Further studies with a larger study population and consistent method for evaluating PD-L1 expression are needed to validate our results.

In conclusion, our results showed that PD-L1 expression in gastrointestinal NEN can be a prognostic marker, with positive PD-L1 expression associated with poor survival and important clinicopathological parameters of higher 
tumor grade and lymph node metastasis. In addition, PD-L1 expression might be used as therapeutic marker in gastrointestinal NEN with which potential candidates for anti-PD-L1 therapy can be selected.

\section{Acknowledgments}

Funding: None.

\section{Footnote}

Reporting Checklist: The authors have completed the PRISMA reporting checklist. Available at http://dx.doi. org/10.21037/tcr-20-3482

Conflicts of Interest: All authors have completed the ICMJE uniform disclosure form (available at http://dx.doi. org/10.21037/tcr-20-3482). The authors have no conflicts of interest to declare.

Ethical Statement: The authors are accountable for all aspects of the work in ensuring that questions related to the accuracy or integrity of any part of the work are appropriately investigated and resolved.

Open Access Statement: This is an Open Access article distributed in accordance with the Creative Commons Attribution-NonCommercial-NoDerivs 4.0 International License (CC BY-NC-ND 4.0), which permits the noncommercial replication and distribution of the article with the strict proviso that no changes or edits are made and the original work is properly cited (including links to both the formal publication through the relevant DOI and the license). See: https://creativecommons.org/licenses/by-nc-nd/4.0/.

\section{References}

1. Digestive System Tumours; WHO Classification of Tumours, 5th Edition, Volume 1. 5th edition. ed. Cree IA, editor. Lyon, France: International Agency for Research on Cancer (IARC), 2019.

2. Hallet J, Law CH, Cukier M, et al. Exploring the rising incidence of neuroendocrine tumors: a population-based analysis of epidemiology, metastatic presentation, and outcomes. Cancer 2015;121:589-97.

3. Yao JC, Hassan M, Phan A, et al. One hundred years after "carcinoid": epidemiology of and prognostic factors for neuroendocrine tumors in 35,825 cases in the United
States. J Clin Oncol 2008;26:3063-72.

4. Chan DL, Clarke SJ, Diakos CI, et al. Prognostic and predictive biomarkers in neuroendocrine tumours. Crit Rev Oncol Hematol 2017;113:268-82.

5. Wu P, Wu D, Li L, et al. PD-L1 and Survival in Solid Tumors: A Meta-Analysis. PLoS One 2015;10:e0131403.

6. Sanmamed MF, Chen L. Inducible expression of B7$\mathrm{H} 1$ (PD-L1) and its selective role in tumor site immune modulation. Cancer J 2014;20:256-61.

7. Guo Y, Yu P, Liu Z, et al. Prognostic and Clinicopathological Value of Programmed Death Ligand-1 in Breast Cancer: A Meta-Analysis. PLoS One 2016;11:e0156323.

8. Zhang M, Dong Y, Liu H, et al. The clinicopathological and prognostic significance of $\mathrm{PD}-\mathrm{L} 1$ expression in gastric cancer: a meta-analysis of 10 studies with 1,901 patients. Sci Rep 2016;6:37933.

9. Bosch F, Bruwer K, Altendorf-Hofmann A, et al. Immune checkpoint markers in gastroenteropancreatic neuroendocrine neoplasia. Endocr Relat Cancer 2019;26:293-301.

10. Busico A, Maisonneuve P, Prinzi N, et al. Gastroenteropancreatic High-Grade Neuroendocrine Neoplasms: Histology and Molecular Analysis, Two Sides of the Same Coin. Neuroendocrinology 2020;110:616-29.

11. Cavalcanti E, Armentano R, Valentini AM, et al. Role of PD-L1 expression as a biomarker for GEP neuroendocrine neoplasm grading. Cell Death Dis 2017;8:e3004.

12. Cives M, Strosberg J, Al Diffalha S, et al. Analysis of the immune landscape of small bowel neuroendocrine tumors. Endocr Relat Cancer 2019;26:119-30.

13. Huang ZY, Fan Y. Programmed cell death-ligand 1 expression and its prognostic significance in completely resected primary small cell carcinoma of esophagus. Transl Cancer Res 2016;5:458-63.

14. Oktay E, Yalcin GD, Ekmekci S, et al. Programmed cell death ligand-1 expression in gastroenteropancreatic neuroendocrine tumors. J BUON 2019;24:779-90.

15. Ono K, Shiozawa E, Ohike N, et al. Immunohistochemical CD73 expression status in gastrointestinal neuroendocrine neoplasms: A retrospective study of 136 patients. Oncol Lett 2018;15:2123-30.

16. Wang C, Yu J, Fan Y, et al. The Clinical Significance of PD-L1/PD-1 Expression in Gastroenteropancreatic Neuroendocrine Neoplasia. Ann Clin Lab Sci 2019;49:448-56.

17. Xing J, Ying H, Li J, et al. Immune Checkpoint Markers in Neuroendocrine Carcinoma of the Digestive System. 
Front Oncol 2020;10:132.

18. Yang $M W, F u$ XL, Jiang YS, et al. Clinical significance of programmed death 1/programmed death ligand 1 pathway in gastric neuroendocrine carcinomas. World J Gastroenterol 2019;25:1684-96.

19. Tierney JF, Stewart LA, Ghersi D, et al. Practical methods for incorporating summary time-to-event data into metaanalysis. Trials 2007;8:16.

20. R Core Team. R: A Language and Environment for Statistical Computing. Vienna, Austria: R Foundation for Statistical Computing, 2017.

21. Schwarzer G. meta: An R package for meta-analysis. R News 2007;7:40-5.

22. Gong J, Chehrazi-Raffle A, Reddi S, et al. Development of PD-1 and PD-L1 inhibitors as a form of cancer immunotherapy: a comprehensive review of registration trials and future considerations. J Immunother Cancer

Cite this article as: Lee W, Kim M, Choi Y, Kim H. PDL1 expression and patient outcomes in gastrointestinal neuroendocrine neoplasm: a meta-analysis. Transl Cancer Res 2021;10(5):2210-2218. doi: 10.21037/tcr-20-3482
2018;6:8.

23. Maggio I, Manuzzi L, Lamberti G, et al. Landscape and Future Perspectives of Immunotherapy in Neuroendocrine Neoplasia. Cancers (Basel) 2020;12:832.

24. Ishii H, Azuma K, Kawahara A, et al. Significance of programmed cell death-ligand 1 expression and its association with survival in patients with small cell lung cancer. J Thorac Oncol 2015;10:426-30.

25. Salhab M, Migdady Y, Donahue M, et al. Immunohistochemical expression and prognostic value of PD-L1 in Extrapulmonary small cell carcinoma: a single institution experience. J Immunother Cancer 2018;6:42.

26. Roach C, Zhang N, Corigliano E, et al. Development of a Companion Diagnostic PD-L1 Immunohistochemistry Assay for Pembrolizumab Therapy in Non-Small-cell Lung Cancer. Appl Immunohistochem Mol Morphol 2016;24:392-7. 


\section{Supplementary}

Table S1 New Castle Ottawa scale result

\begin{tabular}{|c|c|c|c|c|c|c|c|c|c|}
\hline \multirow[b]{2}{*}{ Study } & \multicolumn{4}{|c|}{ Selection } & \multirow{2}{*}{$\begin{array}{c}\text { Comparability } \\
\text { Comparability of cases } \\
\text { and controls on the basis } \\
\text { of the design or analysis }\end{array}$} & \multicolumn{3}{|c|}{ Exposure } & \multirow[t]{2}{*}{ Score } \\
\hline & $\begin{array}{l}\text { Is the case } \\
\text { definition } \\
\text { adequate? }\end{array}$ & $\begin{array}{c}\text { Representativeness of } \\
\text { the cases }\end{array}$ & $\begin{array}{c}\text { Selection of } \\
\text { Controls }\end{array}$ & $\begin{array}{l}\text { Definition of } \\
\text { Controls }\end{array}$ & & $\begin{array}{c}\text { Ascertainment of } \\
\text { exposure }\end{array}$ & $\begin{array}{l}\text { Same method of } \\
\text { ascertainment for cases } \\
\text { and controls }\end{array}$ & $\begin{array}{l}\text { Non- } \\
\text { Response } \\
\text { rate }\end{array}$ & \\
\hline Bösch 2019 & $\star$ & $\star$ & & $\star$ & $\star \star$ & $\star$ & $\star$ & & 7 \\
\hline Busico 2019 & $\star$ & $\star$ & & $\star$ & $\star \star$ & $\star$ & $\star$ & & 7 \\
\hline Cavalcanti 2017 & $\star$ & $\star$ & & $\star$ & $\star \star$ & $\star$ & $\star$ & & 7 \\
\hline Cives 2019 & $\star$ & $\star$ & & $\star$ & $\star \star$ & $\star$ & $\star$ & & 7 \\
\hline Huang 2016 & $\star$ & $\star$ & & $\star$ & $\star \star$ & $\star$ & $\star$ & & 7 \\
\hline Oktay 2019 & $\star$ & $\star$ & & $\star$ & $\star \star$ & $\star$ & $\star$ & & 7 \\
\hline Ono 2018 & $\star$ & $\star$ & & $\star$ & $\star \star$ & $\star$ & $\star$ & & 7 \\
\hline Wang 2019 & $\star$ & $\star$ & & $\star$ & $\star \star$ & $\star$ & $\star$ & & 7 \\
\hline Xing 2020 & $\star$ & $\star$ & & $\star$ & $\star \star$ & $\star$ & $\star$ & & 7 \\
\hline Yang 2019 & $\star$ & $\star$ & & $\star$ & $\star \star$ & $\star$ & $\star$ & & 7 \\
\hline
\end{tabular}

